\title{
XXXVII. On some phœnomena of binocular vision
}

\section{L. Foucault \& J. Regnault}

To cite this article: MM. L. Foucault \& J. Regnault (1849) XXXVII. On some phœnomena of binocular vision , Philosophical Magazine Series 3, 34:229, 269-270, DOI:

10.1080/14786444908646228

To link to this article: http://dx.doi.org/10.1080/14786444908646228

$$
\text { 曲 Published online: } 30 \text { Apr } 2009 .
$$

Submit your article to this journal $\pi$

Џ Article views: 1

Q View related articles $\sqsubset$ 
XXXVII. On some phanomena of Binocular Vision. By MM. L. Foucault and J. Regnault*.

$\mathrm{T}$ a beautiful investigation on the vision of objects of three 1 dimensions, $\mathrm{Mr}$. Wheatstonet states that when two visual fields, or the corresponding elements of the two retinæ, simultaneously receive impressions from rays of different refrangibility, no perception of mixed colours is produced. The assertion of this able philosopher being opposed to the opinion of the majority of those who have attended to the same subject, we have thought it useful to repeat, modify, and extend these experiments. The stereoscope of Mr. Wheatstone offered a simple means of disentangling these delicate observations of all complication capable of injuriously affecting the accuracy of the physiological results.

The recomposition of mixed tints by means of vibrations produced on the retinæ by different coloured rays is beyond doubt. But the aptness varies in a remarkable manner in different individuals; it is possible that it may be exceedingly weak in some persons, and exceptionally null in others.

The tendency of one of the eyes to become inattentive in this kind of experiment is very remarkable when the whole extent of the visual fields is uniformly lighted up by different coloured rays. If we cause an impression to be made on limited and corresponding parts of the retinæ, the power of the attention constantly favours the recomposition. If two coloured rays susceptible, on reaching a white screen, of producing a mixed tint produce the same sensation when acting separately on the corresponding portions of the retinæ, it seems probable that two complementary rays will produce the sensation of white by affecting the corresponding elements of the sensitive membrane.

To prove this recomposition with respect to a great number of complementary tints, and present the phænomenon in all its clearness, we arranged the following experiment :-We affixed to the stereoscope two plane mirrors, forming a variable dihedral angle, the vertical edge of which is placed symmetrically in relation to that of the two glasses of the stereoscope. 'The vertical uprights bearing the grooves for the purpose of introducing the images are perforated by two large circular apertures. In the grooves are placed two glasses, on which are pasted two circular screens of white paper of the same size, and of a diameter less than that of the apertures. Two large luminous rays of complementary tints, obtained by chromatic polarization, are directed horizontally upon the plane mirrors

* From the Comptes Rendus for Jan. 15, 1849.

+ Philosophical Transactions, part $2,1838$. 
which reflect them; they traverse the glasses of the grooves which remain dark; but when reflected irregularly on the circular screens they give two coloured discs, exactly identical as to form and extent, which become the images conveyed by the stereoscope to the corresponding elements of the retinæ. We might, by means of an appropriate disposition of the polarizing apparatus, successively present numerous complementary tints, vary at the same time the intensity of the two coloured images, and modify the intensity of one or other of the images separately.

The following are the physiological results we have observed. When the corresponding elements of the retinæ receive an impression at the same time, the alternations of activity or inertuess of one of the eyes is generally manifested at the commencement of the experiment, and sometimes one of the tints is perceived, and at other times its complementary one; but after a duration of observation, varying considerably according to the individuals, only a single white circle is seen.

When the eyes are in some degree accustomed to this unusual mode of impression, the tendency to recomposition becomes so energetic in some persons, that the screens might present successively all the complementary tints which the apparatus furnishes without there being any sensation corresponding to the colours; only white light is seen.

On diminishing the intensity of one of the colours, the other remaining constant, recomposition still takes place; but the white disc appears to become covered more or less strongly with the predominant tint.

If the intensity of the complementary rays is varied in the same manner for the two collections of rays, the recomposition is made with greater facility at the commencement of the observation, as their intensity is more moderated.

Of the complementary rays which we have examined, the sensible blue and the yellow tints are best adapted for the experiment, and immediately furnish the sensation of white.

We believe that this phænomenon is owing to the circumstance, that the accommodation of the eyes being the same for these groups of rays, according to the portions of the spectrum which they occupy, the efforts necessary to produce recomposition are on that account considerably less.

We find that, saving exceptional cases, the sensation of white light may be produced by any two complementary chro. matic impressions in each of the eyes; that the sensation solely of white arising from two complementary rays is independent of any mutual action of these rays externally to the visual apparatus; that the luminous impressions produced on the retinæ retain their properties even to the innermost recesses of the brain. 